\title{
Provisional Study of Kuwait Adult Hematology Reference Range
}

Keywords: Complete blood count; Ethnicity; Genetics; Environmental; Standardized; Intervals

\begin{abstract}
Introduction: Hematology reference range provides valuable information for the correct interpretation of results for proper diagnosis and treatment. Previous studies have shown that hematology reference range may vary in people of various continents.
\end{abstract}

Method: From 95,501 subjects a normal 500 females and 500 male Kuwaiti fulfilling the criteria of normal individuals were chosen in this study from October 2012 to March 2013 with no medical follow up required until March 2016 study. The $\mathrm{Hb}$ concentration; $\mathrm{HCT}$ ratio; $\mathrm{RBC}$ count, $\mathrm{MCV} ; \mathrm{MCH} ; \mathrm{MCHC}$; red cell distribution width (RDW); WBC count; absolute neutrophil count (ANC); lymphocyte, monocyte, eosinophil and basophil counts; PLT count; platelet mean volume (PMV) were evaluated and compared with adult UK hematology reference range (AUK-HRR) which our analyzer standardized according to it.

Results: The obtained hematology reference range in this study considered the adult provisional Kuwaiti hematology reference range (APK-HRR). The APK-HRR categorized patients with slight microcytic hypochromic anemia and a slightly increased RBC, WBC and platelet count within the normal Kuwaiti population.

Conclusion: A significant difference was observed between APK HRR and AUK-HRR when the slight microcytic hypochromic picture and high RBC count in AUK-HRR found within the normal range of APKHRR. The slightly high WBC and platelets count in APK-HRR excluded any infection or underlying disease in Kuwaiti population. The regional factors including ethnicity, genetics, and environment could affect the complete blood count. Standardizing local or regional hematology reference range should be mandatory.

\section{Introduction}

Laboratory reference range provides the correct interpretation of results. However, the reference range followed by many laboratories worldwide is according to the reference ranges of another country. The concept of reference range appears simple; but obtaining samples from a healthy population and establishing an appropriate range is a complex and difficult process. Each country is responsible for ensuring the validity of its reference ranges $[1,2]$. For effective interpretation and distinction in health and disease, it is necessary to establish accurate reference range of a population living in a certain region. Hematology reference range is only applicable to specific analyzerreagent combinations, and is subject to demographic and preanalytical variables specific to that local laboratory; these variables should be determined for each parameter [3]. The International Federation of Clinical Chemistry and the Clinical and Laboratory Standards Institute recommend that reference range should be established for each region. In appropriate reference range can lead to unnecessary follow-up investigations and treatment and mismanagement of

\section{Journal of}

Hematology \& Thrombosis

\section{Hassan A. Al-Jafar* \\ Department of Heamtology, Amiri Hospital, Kuwait City, Kuwait}

*Address for Correspondence:

Hassan A. Al-Jafar, Consultant Haematologist, Amiri Hospital, Kuwait City, Kuwait; E-mail: cbc9@hotmail.com

Submission: 07 May, 2016

Accepted: 16 May, 2016

Published: 21 May, 2016

Copyright: (๑) $2016 \mathrm{Al}$-Jafar HA. This is an open access article distributed under the Creative Commons Attribution License, which permits unrestricted use, distribution, and reproduction in any medium, provided the original work is properly cited.

Reviewed \& Approved by: Dr. Raul H. Morales-Borges, American Red Cross in San Juan, Practices, Ashford Institute of Hematology \& Oncology, USA

patients [4-6]. Genetic factors have been shown to influence blood cell parameters $[7,8]$. The European population reference range is not identical to the reference range of the population of other continents [9]. The differences could be related to the difference in ethnicity and genetics [10].

The blood specimens of normal African adults were observed to have lower $\mathrm{Hb}, \mathrm{HCT}, \mathrm{RBC}$ count, $\mathrm{MCV}$, and neutrophil and platelet counts, and higher monocyte and eosinophil counts. Based on such findings, it was clear that the use of reference values generated from distant or dissimilar populations may misguide the local interpretation of blood cell count findings causing not only misdiagnosis but also misreporting of adverse events [11]. Therefore, in this study, we compared our obtained results as adult provisional Kuwaiti hematology reference range (APK-HRR) with the adult United Kingdom reference range (AUK-HRR), which is in use as a reference standard in our laboratory to interpret the results of the Kuwaiti population since decades. To our knowledge, this was the first time that such standardization to compare our local hematology reference values with UK reference values was performed in our country.

\section{Methods}

In this study, CBC analyses were performed using a Coulter LH750/755 analyzer for Kuwaiti patients who visited Amiri hospital for various reasons. Amiri hospital provides services to the people in the great capital region of Kuwait. It serves about 500,000 people. The blood results were collected from adult Kuwaiti individuals selected from the electronic data from October 2012-March 2013, after ensuring from the computer system registry that the selected individuals did not follow-up for any chronic disorders over up to March 2016. The number of subjects in our study period was 95,501. An adult 500 females and 500 adult male Kuwaiti fulfilling the criteria of normal individuals were chosen in this study. The $\mathrm{Hb}$ concentration; HCT ratio; RBC count, MCV; $\mathrm{MCH}$; MCHC; red cell distribution width (RDW); WBC count; absolute neutrophil count 
ISSN: $2380-6842$

Table 1A: The important differences between the APK-HRR and the AUKHRR for both females and males.

\begin{tabular}{|c|c|c|c|c|c|}
\hline $\begin{array}{c}\text { Female } \\
(\mathrm{N}=500)\end{array}$ & Median & (Mean \pm SD & unit & APK-HRR & AUK-HRR \\
\hline RBC & 4.48 & $4.50 \pm 0.45$ & $10 \% / \mathrm{L}$ & $4.1-5.0$ & $3.8-4.8$ \\
\hline $\mathrm{Hb}$ & 127 & $126 \pm 13.3$ & $g / L$ & $113-139$ & $120-150$ \\
\hline HСT & 0.38 & $0.38 \pm 0.04$ & L/L & $0.34-0.42$ & $0.36-0.46$ \\
\hline MCV & 86.0 & $84.3 \pm 7.33$ & $f / L$ & $77-92$ & $83-101$ \\
\hline $\mathrm{MCH}$ & 29.0 & $28.0 \pm 2.87$ & pg. & $25-31$ & $27-32$ \\
\hline MCHC & 333 & $332 \pm 9.12$ & $\mathrm{~g} / \mathrm{L}$ & $323-341$ & $315-345$ \\
\hline RDW & 13.7 & $14.2 \pm 1.80$ & $\%$ & $12.4-16$ & $11.6-14$ \\
\hline WBC & 8.00 & $8.26 \pm 2.83$ & $10^{9} / \mathrm{L}$ & $5.4-11$ & $4.0-10$ \\
\hline NEUT $\%$ & 60.7 & $60.9 \pm 12.4$ & $\%$ & $49-73$ & $40-80$ \\
\hline LYMP \% & 29.6 & $29.2 \pm 10.8$ & $\%$ & $18-40$ & $20-40$ \\
\hline MONO \% & 7.00 & $7.27 \pm 2.39$ & $\%$ & $4.9-10$ & $2.0-10$ \\
\hline ESO \% & 1.60 & $2.09 \pm 2.01$ & $\%$ & $0.1-4$ & $1.0-6$ \\
\hline BAS $\%$ & 0.40 & $0.48 \pm 0.34$ & $\%$ & $0.1-1$ & $<1.0-2$ \\
\hline NEUT A & 4.75 & $5.22 \pm 2.59$ & $10^{9} / \mathrm{L}$ & $2.6-8$ & $2.0-7$ \\
\hline LYMP A & 2.20 & $2.26 \pm 0.82$ & $10 \% / L$ & $1.4-3$ & $1.0-3$ \\
\hline MONO A & 0.50 & $0.57 \pm 0.21$ & $10^{9} / \mathrm{L}$ & $0.4-1$ & $0.2-1$ \\
\hline EOS A & 0.12 & $0.17 \pm 0.22$ & $10 \% / \mathrm{L}$ & $<0.01-0.4$ & $0.02-0.1$ \\
\hline BAS A & 0.03 & $0.04 \pm 0.03$ & $10^{9} / \mathrm{L}$ & $0.01-0.1$ & $0.02-0.1$ \\
\hline PLTCNT & 271 & $277 \pm 73.0$ & $10^{\%} / \mathrm{L}$ & $204-350$ & $150-410$ \\
\hline MPV & 8.50 & $8.62 \pm 1.08$ & $\mathrm{fL}$ & $7.5-10$ & $7.0-11$ \\
\hline
\end{tabular}

(ANC); lymphocyte, monocyte, eosinophil, and basophil counts; PLT count; platelet mean volume (PMV) were evaluated and compared with the AUK-HRR.

\section{Data source}

The collected 1000 individuals were carefully collected from the electronic data system, age range, 18-96 years. The inclusion criteria were normal adult Kuwaiti men and women with normal blood sugar and lipid, liver, and renal profiles. The entire study sample had no follow-up in any medical or outpatient surgical departments up to March 2016 to confirm that no anemia due to chronic disorders. We excluded the patients with low serum ferritin level and abnormal high performance liquid chromatography (HPLC), blood sugar, renal function test, liver function test, and lipid profile to avoid inclusion of patients with anemia due to chronic disorders.

\section{Results}

The obtained APK-HRR and the AUK-HRR were as follow respectively:

For the female group: Hb was 113-139 and (120-150); HCT, 0.340.42 and (0.36-0.46); RBC count, 4.1-5.0 and (3.8-4.8); MCV, 77-92 and (83-101); $\mathrm{MCH}, 25-31$ and (27-32); MCHC, 323-341 and (315$345)$; RDW, 12.4-16 and (11.6-14); WBC count, 5.4-11 and (4.0-10); ANC, 2.6-8 and (2.0-7); PLT count, 204-350 and (150-410); PMV, 7.5-10 and (7-11), respectively.
For the male group: Hb was 138-164 and (130-170); HCT, 0.410.50 and (0.40-0.50); RBC count, 4.7-5.8 and (4.5-5.5); MCV, 80-93 and (83-101); $\mathrm{MCH}, 26-33$ and (27-32); MCHC, 327-347 and (315345); RDW, 12.5-15 and (11.6-14); WBC count, 5.9-12 and (4.0-10); ANC, 2.7-8 and (2.0-7); PLT count, 184-304 and (150-410); PMV 7.510 and (7-11), respectively.

\section{Discussion}

This study aimed to provide local APK-HRR and to compare it with the AUK-HRR, as our complete blood count analyzer standardized since decades according to the AUK-HRR. The results of APK-HRR found different from those of AUK-HRR. In both female and male Tables $1 \mathrm{~A}$ and $1 \mathrm{~B}$; the variations detected were significant for changing the diagnosis or treatment plans. Normal reference values are commonly used not only to assess the overall health but also to diagnose and monitor diseases and to determine the safety and efficacy of interventions, including treatment [12]. The international council for standardization in hematology has outlined the theory of reference values and the procedures of obtaining normal reference range [13]. Subjects with no particular disease and with normal $\mathrm{Hb}$ electrophoresis, ferritin levels, serum iron, TIBC, and CBC were considered as normal [14]. Normal reference values were usually defined as the values encompassing the central $95 \%$ of specimens and equating to 2 standard deviations on either side of the mean [15].

APK-HRR is significantly different from AUK-HRR. The slight higher $\mathrm{RBC}$ count and the lower $\mathrm{Hb}, \mathrm{MCV}, \mathrm{MCH}$ values in many patients, are normal according to APK-HRR but they are considered

Table 1B: The important differences between the APK-HRR and the AUK-HRR for both females and males.

\begin{tabular}{|c|c|c|c|c|c|}
\hline $\begin{array}{c}\text { Male } \\
(\mathrm{N}=500)\end{array}$ & Median & (Mean \pm SD & unit & APK-HRR & AUK-HHR \\
\hline RBC & 5.22 & $5.23 \pm 0.57$ & $10 \% / L$ & $4.7-5.8$ & $4.5-5.5$ \\
\hline $\mathrm{Hb}$ & 152 & $151 \pm 13.2$ & $g / L$ & $138-164$ & $130-170$ \\
\hline HCT & 0.45 & $0.45 \pm 0.04$ & L/L & $0.41-0.50$ & $0.40-0.50$ \\
\hline MCV & 87.0 & $86.2 \pm 6.55$ & $f / L$ & $80-93$ & $83-101$ \\
\hline $\mathrm{MCH}$ & 30.0 & $29.1 \pm 2.66$ & pg. & $26-32$ & $27-32$ \\
\hline МСHC & 338 & $337 \pm 9.71$ & $g / L$ & $327-347$ & $315-345$ \\
\hline RDW & 13.4 & $13.7 \pm 1.16$ & $\%$ & $12.5-15$ & $11.6-14$ \\
\hline WBC & 8.35 & $8.76 \pm 2.88$ & $10 \% / L$ & $5.9-12$ & $4.0-10$ \\
\hline NEUT \% & 58.6 & $59.2 \pm 13.0$ & $\%$ & $46-72$ & $40-80$ \\
\hline LYMP \% & 29.7 & $29.4 \pm 11.3$ & $\%$ & $18-41$ & $20-40$ \\
\hline MONO $\%$ & 7.70 & $8.03 \pm 2.45$ & $\%$ & $5.6-10$ & $2.0-10$ \\
\hline ESO \% & 2.10 & $2.82 \pm 2.72$ & $\%$ & $0.1-6$ & $1.0-6$ \\
\hline BAS $\%$ & 0.40 & $0.47 \pm 0.29$ & $\%$ & $0.2-1$ & $<1.0-2$ \\
\hline NEUT A & 4.60 & $5.38 \pm 2.72$ & $10 \% / L$ & $2.7-8$ & $2.0-7$ \\
\hline LYMP A & 2.30 & $2.39 \pm 0.84$ & $10 \% / \mathrm{L}$ & $1.5-3$ & $1.0-3$ \\
\hline MONO A & 0.60 & $0.68 \pm 0.25$ & $10 \% / \mathrm{L}$ & $0.4-1$ & $0.2-1$ \\
\hline EOS A & 0.17 & $0.24 \pm 0.24$ & $10 \% / \mathrm{L}$ & $<0.01-0.5$ & $0.02-0.5$ \\
\hline BAS A & 0.04 & $0.04 \pm 0.03$ & $10^{9} / \mathrm{L}$ & $0.01-0.1$ & $0.02-0.1$ \\
\hline PLTCNT & 242 & $244 \pm 59.8$ & $10^{9} / \mathrm{L}$ & $184-304$ & $150-410$ \\
\hline MPV & 8.50 & $8.52 \pm 1.04$ & $\mathrm{fL}$ & $7.5-10$ & $7.0-11$ \\
\hline
\end{tabular}




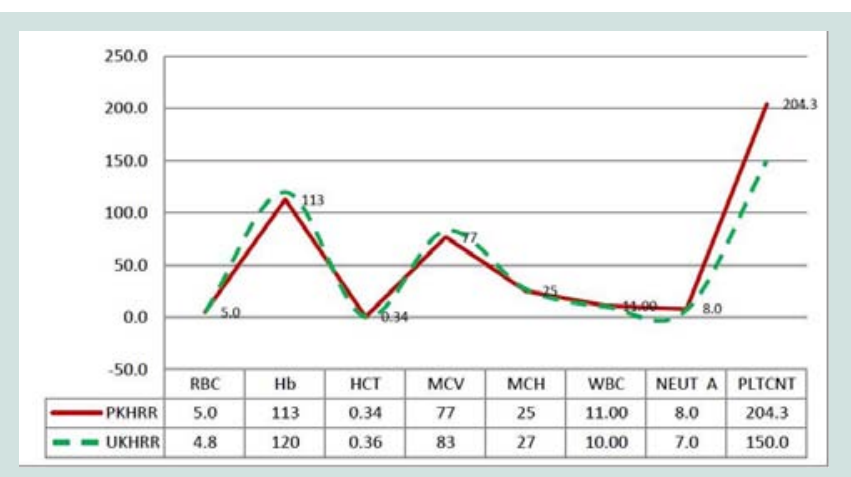

Figure 1: Female adult group levels differences of APK-HRR \& AUK-HRR which could change the diagnosis and treatment plan.

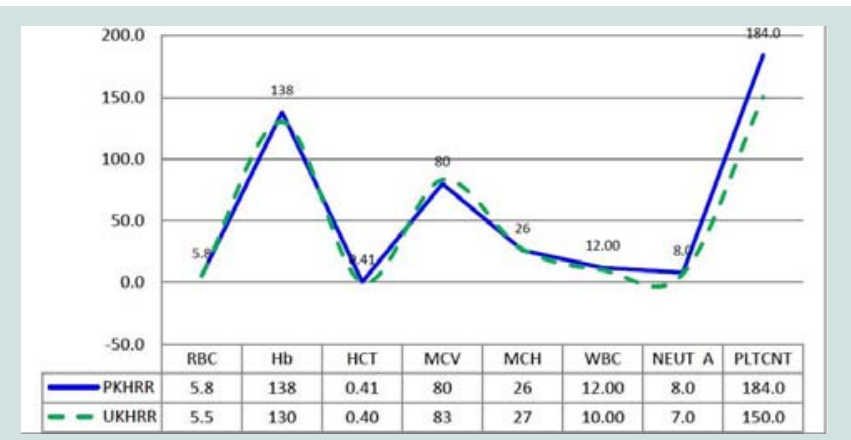

Figure 2: Male adult group levels differences of APK-HRR \& AUK-HRR which could change the diagnosis and treatment plan.

anemic according to AUK-HRR Tables $1 \mathrm{~A}$ and $1 \mathrm{~B}$. In the presence of normal serum ferritin and normal HPLC this high RBC count with the microcytic hypochromic picture give a diagnosis of alpha thalassaemia according to AUK-HRR but it is within the normal range according to APK-HRR and Figures 1 and 2. Ethnicity has been reported to contribute towards $\mathrm{CBC}$ differences. Other factors, such as environmental and nutritional status, may also play a great role. This was supported by the differences observed between South Indians in Chennai and Malaysian Indians, even though both the population groups had the same ethnic origin [16]. Studies from France indicate that individual variations, particularly, ethnic characteristics, cannot be ignored [17].

The WBC counts, according to the APK-HRR and AUK-HRR were 5.4-11 and (4.0-10) for women and 5.9-12 and (4.0-10) for men, respectively. The ANCs, according to the APK-HRR and AUK-HRR were 2.6-8 and (2.0-7) for women and 2.7-8 and (2.0-7) for men, respectively. Both the WBC and ANC counts are higher in APK-HRR than in AUK-HRR without any infection or any another underlying disease. The differences in the absolute values of lymphocytes, monocytes, eosinophils, and basophils were not significant. Another study reported that the total WBC and neutrophil counts of Africans and West Indians were significantly lower than those of northern Europeans, whereas the monocyte and eosinophil counts were higher. In addition, their counts were significantly lower than those of Indian and Oriental subjects [18], thus confirming that regional data is mandatory to evaluate respective reference range and to establish normal reference range. The platelets counts, according to the APK-
HRR and AUK-HRR were 204-350 and (150-410) in women and 184-304 and (150-410) in men, respectively, which mean that APKHRR has a higher limit of platelets count than AUK-HRR. However, according to the international treatment consensus, it does not affect the treatment strategy of thrombocytopenia or thrombocytosis. Therefore, each population must establish its own normal reference range values for use in clinical assessments [19]. Based on such findings, it is clear that the use of international reference values generated from distant or dissimilar populations may misguide the local interpretation of blood cell counts findings, thus causing not only misdiagnosis but also misreporting of adverse events, and affecting the treatment plans $[11,20]$.

\section{Limitation}

The hematology reference range in this study was calculated from a large Kuwaiti population in the capital area; however, only 1,000 individuals were selected from the 95,501 who visited our institute over 6 months. Furthermore, we did not have the HPLC and serum ferritin values of all the selected subjects. In patients with normal serum ferritin and normal HPLC pattern still they could be alpha thalassemia trait, but it is impossible to perform DNA analysis for such a huge sample number.

The strengthening point in this study that in many well investigated families with no family history of hemoglobinopathy, their $\mathrm{CBC}$ showed high $\mathrm{RBC}$, low $\mathrm{Hb}, \mathrm{MCV}$ and $\mathrm{MCH}$ according to AUK-HRR but they are normal according to APK-HRR. However, because of the significant results, this study must be conducted in other regions of this country and the samples should be collected from healthy volunteers and the molecular DNA analysis to be applied.

\section{Conclusion}

The results of this study showed the importance of obtaining local or regional hematology reference range. Because the other regional reference range does not necessary reflect the actual local reference range, so there could be a significant effect on both the diagnosis and treatment. This study should be repeated in other regional areas of Kuwait to confirm the findings, which are extremely important in confirming anemia and hemoglobinopathy in many patients according to the adult provisional Kuwait-Hematology reference range results. The differences between the APK-HRR and the AUKHRR could be related to ethnic, genetic, or environmental reasons.

\section{Study Approval}

This study was approved by the Joint Committee for the Protection of Human Subjects in Research, reference number: VDR/179, subject title: "Detecting the normal hematology values and the incidence of the different types of anemia in random samples obtained from Kuwaiti people referred to Al-Amiri hospital in the great capital area".

\section{References}

1. Wangkheimayum S (2013) Determination of reference values of some routine clinical biochemistry parameters of apparently healthy North Indian subjects. J Biochem Res 1: 1-6.

2. Totali M, Gligor FG, Bojita M, Grigore C, Grigore C (2013) Determining hemoglobin reference values in children and teenagers from Sibiu area. Rev Romana Med Lab 21: 39-45.

3. Roshan TM, Rosline H, Ahmed SA, Rapiaah M, Wan Zaidah A, et al. (2008) 
Hematological reference values of healthy Malaysian population. Int J Lab Hematol 31: 505-512.

4. Briggs C, Culp N, Davis B, d'onofrio G, Zini G, et al. (2014) ICSH guidelines for the evaluation of blood cell analysers including those used for differential leucocyte and reticulocyte counting. Int J Lab Hematol 36: 613-627.

5. Dosoo DK, Kayan K, Adu-Gyasi D, Kwara E, Ocran J, et al. (2012) Haematological and biochemical reference values for healthy adults in the middle belt of Ghana. PLoS One 7: e36308.

6. Solberg HE, Stamm D (1991) IFCC recommendation: The theory of reference values. Paer 4. Control of analytical variation in the production, transfer and application of reference values. J Automat Chem 13: 231-234.

7. Haileamlak A, Muluneh AT, Alemseged F, Tessema F, Woldemichael K, et al. (2012) Hematoimmunological profile at gilgel gibe field research center, southwest Ethiopia. Ethiop J Health Sci 22(S): 39-50.

8. Akinbo BD, Atere AD, Fatunade HB, lyabor NO (2015) Haematological indices and absolute CD4 counts of apparently healthy population in Ondo State, Nigeria. Br J Med Med Res 8: 717-723.

9. Palacpac NM, Ntege E, Balikagala B, Yeka A, Shirai H, et al. (2014) Hematological and biochemical data obtained in rural northern Uganda. Int $J$ Environ Res Public Health 11: 4870-4885.

10. Institute of Medicine (US) Committee on Assessing Interactions among Social, Behavioral, and Genetic Factors in Health; Hernandez LM, Blaze DG (2006) Genes, behavior, and the social environment: moving beyond the nature/nurture debate. National Academies Press, Washington (DC).

11. Kironde F, Sekikubo M, Naiwumbwe H, Namusoke F, Buwembo W, et al (2013) Hematology and blood serum chemistry reference intervals for children in Iganga district of Uganda. Health 5: 1261-1267.
12. Garcia-Basteiro AL, Bassat Q, Alonso PL (2012) Approaching the target: the path towards an effective malaria vaccine. Mediterr $\mathrm{J}$ Hematol Infect Dis 4 e2012015.

13. Ramezani A, Shams M, Zarinfar N, Banifazl M, Aghakhani A, et al. (2014) Hematological reference values for healthy males in the central part of Iran. Iran J Pathol 9: 50-55.

14. Rustad P (2003) Reference intervals for 25 of the most frequently used properties in clinical chemistry. Proposal by Nordic Reference Interval Project (NORIP).

15. Segolodi TM, Henderson FL, Rose CE, Turner KT, Zeh C, et al. (2014) Normal laboratory reference intervals among healthy adults screened for a HIV pre-exposure prophylaxis clinical trial in Botswana. PLoS One 9: e93034.

16. Ambayya A, Su AT, Osman NH, Nik-Samsudin NR, Khalid K, et al. (2014) Haematological reference intervals in a multiethnic population. PLoS One 9: e91968.

17. Troussard X, Vol S, Cornet E, Bardet V, Couaillac JP, et al. (2014) Full blood count normal reference values for adults in France. J Clin Pathol 67: 341-344.

18. Bain B, Seed M, Godsland I (1984) Normal values for peripheral blood white cell counts in women of four different ethnic origins. J Clin Pathol 37: 188-193.

19. Buseri FI, Siaminabo IJ, Jeremiah ZA (2010) Reference values of hematological indices of infants, children, and adolescents in Port Harcourt, Nigeria. Pathol Lab Med Int 2: 65-70.

20. Gomez P, Coca C, Vargas C, Acebillo J, Martinez A (1984) Normal referenceintervals for 20 biochemical variables in healthy infants, children, and adolescents. Clin Chem 30: 407-412.

\section{Acknowledgements}

Great thankful for the haematology laboratory staff in Amiri Hospital for facilitating this work. 